\title{
Weight Loss As a Sociocultural Practice of Creating a Demanded Body in the Students' Community
}

\section{Ludmila Russkikh¹ and Elena Grunt ${ }^{2}$}

${ }^{1}$ South Ural State University (national research university), Chelyabinsk, Russian Federation

${ }^{2}$ Ural Federal University named after the first President of Russia B. N. Yeltsin, Yekaterinburg, Russian Federation

\section{Abstract}

This article discusses the sociocultural practice of weight loss as a mean of a demanded body design in the student's community. The study was conducted in 2019 at the South-Ural State University (National Research University) in Chelyabinsk, in Russia. The research methodology uses quantitative approach. 350 students were questioned. The objectives of the research were to study students' perceptions of the body in demand and methods of weight loss for the construction of the body in demand.

Corresponding Author:

Ludmila Russkikh

ludmilaruss@mail.ru

Published: 21 January 2021

Publishing services provided by Knowledge E

(c) Ludmila Russkikh and Elena Grunt. This article is distributed under the terms of the Commons Attribution License, which permits unrestricted use and redistribution provided that the original author and source are credited.

Selection and Peer-review under the responsibility of the XXIII International Conference Conference Committee. The study was based on sociological theories: such as body theory, theory of social / sociocultural practice and the social constructivism theory. The survey has revealed a strong dependence of students' desire to lose weight on the common opinion. $79 \%$ of those who have been told about his / her stoutness want to lose weight, and only $24 \%$ of those who have not been told about his / her stoutness has the desire to lose weight. A strong relationship was also found between the students' attempt and the desire to lose weight, depending on the presence of excess pounds. The authors draw conclusions about the students' gender difference in ideas about the demanded female and male body. For girls, the harmony of the female body is more important than such a characteristic for men (despite the fact that this is their only requirement), as well as the relief, which for the boys in the perception of the female body was not important. But the requirements for the lack of undesirable body characteristics are the same. The study has shown that the majority of respondents $(72.0 \%)$ do not consider model parameters of the figure to be the standard. However, girls still relate to such ideals somewhat more favorably than boys. Perhaps this is due to the greater exposure of girls to the influence of the media, public opinion and advertising. The dependence of the attempt and desire to lose weight on the adoption of model parameters for the standard was not found. The study has determined that for the majority of students the sociocultural practice of weight loss is an important means of constructing their physicality. However, for only one third of the respondents, it turned out to be effective. At the same time, students are not ready for more radical measures to change their physicality.

Keywords: demanded body, students' community, sociocultural practice of losing weight, a demanded body design 


\section{Introduction}

In each historical and cultural epoch, its own ideal of beauty and a demanded human body are formed. It depends on the socio-economic conditions of a person's life, his / her status, culture, gender, etc. [11, 21]. Meanwhile, only at the end of the $X X$ and the beginning of the $X X 1$ st centuries the body becomes an independent value formed by a person using various sociocultural practices. In modern society, stereotypes about which human body is in demand are being formed [16]. Dissatisfaction with one's own body and aiming for an ideal makes a person uses various sociocultural practices for his / her body design: plastic surgery [4, 7]; diet and weight loss [19], physical education and sport [8], etc. In the XX1st century, the industry of "designing corporeality" focused on satisfying the needs of the individual in certain types of corporeality was created. Sociocultural practices of body design are associated with the achievements of modern medicine and biotechnology development.

In these conditions the body design problem becomes one of the key in European $[2,4,7,9,10,22]$ and Russian $[1,15,17,18,20]$ scientific discourse.

An interest in the concept of social practice in modern sociology renews in the context of a practice turn- the emphasis of sociology on everyday life, as well as the consideration of habitual and repeated actions as an independent field of research and the formation of a new approach to the society study based on the concept of "social practices" $[3,5,6,13,14]$. Speaking about social practices, A. Schutz writes: "What at first was only the result of the repeated actions of individuals' groups, the next generation is already perceived as a given, subject only to repetition, as natural for the individual in the surrounding space as the physical objects present in him. Social practices characterize sustainability, reproduction, mass character and normalization" [23, 43]. According to P. Bourdieu, social practices have a dual structure. On the one hand, they are determined by the social environment, on the other hand, they influence the environment, changing its structure. It should be noted that the practices are carried out using the tool of the body. The issue of "corporeality" practices is addressed in the works of P. Bourdieu [5] and E. Giddens [14]. The individual's body can be considered as a repository of social practices. The restrictions imposed by the body on human capabilities are primary in the organization of social practices in time and space. Sociocultural practice in the context of the life process is a variety of social practice. It provides the individual with the production of a new sociocultural experience, as well as the experience of overcoming problems, life conflicts and the optimal choice in solving problems. The peculiarities of sociocultural practice as a goal-oriented, expedient, and consistent activity include 
the fact that it is realized both in a form already known to the community and in the form of individual self-construction in the process of personal creative self-expression. Moreover, the objects of self-construction such as nature and its objects, educational organizations, surrounding communities, social networks, the human body, etc. create the conditions for the implementation of trial practical experience in an event-specific situation for an individual. Sociocultural practice acts as the cultural norm of innovative processes created by life situations of practical activity. The organization of sociocultural practice is carried out on the basis of the persons' activity, which is leading for a certain age, in the context of the subjects' responsible sociocultural actions formation. Thus, culture forms the sociocultural space of such a practices.

Although the issues related to student's sociocultural practices are rather broadly explored, there remains a lack of understanding as to how students use weight loss as sociocultural practice of creating a demanded body. Our study seeks to fill this gap.

\section{Methods and Methodology}

The objectives of the research were to study students' perceptions of the demanded body and means of weight loss for the demanded body design.

The study was based on the sociological theory of the body, the theory of social / sociocultural practice, and the social constructivism theory.

The study was conducted at the South Ural State University, in Chelyabinsk, a large Ural megalopolises in 2019. The survey used a quantitative strategy - a questionnaire survey $(n=350)$. 350 students were questioned (equal proportions of $50 \%$ boys and girls aged 18 to 24 years), both undergraduate and graduate students. The respondents were questioned using the purposive sampling approach. The questionnaire consisted of 66 questions, some of which were reformulated after a pilot study. For example the question "What is your dissatisfaction with? (several options are possible)" and the question "Tell me, what was the impetus for the beginning of weight loss for you? (several options are possible) were not understandable for the respondents.

A document analysis, statistics and secondary data analysis were carried out.

The results were processed with SPSS - specialized software for processing sociological and marketing information. 


\section{Results and Discussion}

The study has shown that a high degree of satisfaction with the body is expressed mostly by students who are not on the heavy side (25.0\%), and low degree is expressed by students who are on the heavy side (17.0\%). Thus, fairly slender respondents are satisfied with their bodies. This is understandable and logical - no one bears down on them and no one impose the idea that something is wrong with their appearance. Students are characterized by a high degree of satisfaction for those who have never been told about the presence of excess pounds (23\%).

The survey has revealed a strong dependence of students' desire to lose weight on the common opinion. $79 \%$ of those who have been told about his / her stoutness want to lose weight, and only $24 \%$ of those who have not been told about his / her stoutness has the desire to lose weight. A strong relationship was also found between the attempt and the desire to lose weight, depending on the presence of excess pounds. The more excess pounds the respondent has, the stronger his / her desire to lose weight and the more attempts to lose weight. It should be noted that only $90 \%$ of those who want to lose weight actually make this attempt. Meanwhile, the majority of respondents from this group are not satisfied with their bodies.

Gender analysis has revealed a different attitude towards the demanded body among the students. $60 \%$ of the respondents (56\% of men and $65 \%$ of women) believe that more demands are made on the appearance of women than on the appearance of men, $31 \%$ ( $29 \%$ of men and $33 \%$ of women) think that the requirements are approximately the same, and only $5 \%$ of students (10\% of men and $1 \%$ of women) believe that more demands are made for men appearance. For men, of course, some criteria of the male body are important, but in general their requirements are much lower than the women requirements. Women have a sharper attitude towards men, namely: the requirements for the presence of positive indicators (such as harmony, muscle relief, a man of slender make and etc.), as well as the lack of negative ones (for example, the presence of a spare tire, stoutness and etc.) is higher than that of the men themselves, and they, accordingly, are more loyal to the male body. Men are more critical of the female body than theirs, their requirements are higher, and women are even more critical of their bodies than men. For girls, the harmony of the female body is more important than such a characteristic for men (despite the fact that this is their only requirement), as well as the body relief, which for the boys in the perception of the female body was not important. But the requirements for the lack of undesirable body characteristics are the same. 
The study has shown, according to the number of criteria, more demands are made on the male body than on the female, however, when considering the degree of importance of these requirements, one can notice the opposite tendency: the presence of undesirable traits in the male body is not as noticeable as in the female one. Men are more critical of the female body than their own. And women assess male and female bodies in approximately the same way, but nevertheless, they are more demanding of themselves.

The study has fixed the image of an ideal body in a student's community. It is the same as mass- media show: a tall man with a slender muscular body and perfect proportions. The ideal image of a woman is her slenderness, the correct proportions and a flat belly. The girls themselves believe that body plasticity is also important.

The majority of the respondents believe that one of the important sociocultural practices of their body design is weight loss. The most popular methods of weight loss for girls are: diet (92\%), the beginning of physical education (68\%), fasting days (38\%) and calories estimation (32\%). The least popular methods are cosmetic procedures (10\%), teas and herbs for weight loss (8\%), metabolic acceleration (6\%), baths and saunas (5\%). The most popular methods of weight loss for young men are diet $(75 \%)$, the beginning of physical education (43\%), intense physical training (40\%) and fasting (33\%). The least popular methods are calorie reduction (10\%), pills and drugs (5\%) and cosmetic procedures (3\%). It is also worth noting two curious facts: neither of girls used such drugs as diet pills, but they were also used by young men; neither of young men used teas and herbs for weight loss, but girls used them.

Respondents were asked about the reasons for weight loss (Table 1). The most popular answer was that people lose weight because they set heart on the ideal and an ideal body (55\%). Men who attempted to lose their weight tend to think so. Most likely, they themselves, losing weight, try to get closer to the ideal. We correlated the respondents who was on the same page with the reason for weight loss, and found out that $42 \%$ of those who tried to lose weight for the sake of beautiful appearance, they considered the desire for ideal to be the reason for weight loss.

The amount is more than $100 \%$, because the respondent could select several answer options at the same time.

The second most popular answer is that they wanted to change their lives (53\%). Mostly this opinion is shared by those respondents who attempted to lose their weight. Answers are a little less common that weight loss was caused by health problems (47\%), low self-esteem - 38\% (and women tend to think so), the influence of the media and society (29\%), problems in personal life (24\%) (such opinion is also more likely 
TABLE 1: The dependence of the causes of students' weight loss on gender and attempts to lose weight (a percentage of the number of questioned respondents)

\begin{tabular}{|c|c|c|c|c|c|}
\hline \multirow{2}{*}{$\begin{array}{l}\text { Causes of weight } \\
\text { loss }\end{array}$} & \multirow{2}{*}{$\begin{array}{c}\text { In the whole } \\
\text { sample }\end{array}$} & \multicolumn{2}{|c|}{ Women } & \multicolumn{2}{|c|}{ Men } \\
\hline & & $\begin{array}{l}\text { students } \\
\text { trying to } \\
\text { lose weight }\end{array}$ & $\begin{array}{c}\text { students } \\
\text { not trying to } \\
\text { lose weight }\end{array}$ & $\begin{array}{l}\text { students } \\
\text { trying to } \\
\text { lose weight }\end{array}$ & $\begin{array}{c}\text { students } \\
\text { not trying to } \\
\text { lose weight }\end{array}$ \\
\hline $\begin{array}{l}\text { Set heart on the } \\
\text { ideal and an ideal } \\
\text { body }\end{array}$ & 55.3 & 61.9 & 67.3 & 57.9 & 37.8 \\
\hline $\begin{array}{l}\text { The desire to } \\
\text { change their life }\end{array}$ & 52.7 & 69.8 & 46.9 & 50.0 & 43.2 \\
\hline $\begin{array}{l}\text { The Health } \\
\text { problems }\end{array}$ & 47.3 & 52.4 & 49.0 & 34.2 & 48.6 \\
\hline Low self-esteem & 37.9 & 47.6 & 42.9 & 23.7 & 33.8 \\
\hline $\begin{array}{l}\text { The influence of } \\
\text { the media and } \\
\text { society }\end{array}$ & 29.0 & 34.9 & 40.8 & 21.1 & 20.3 \\
\hline $\begin{array}{l}\text { Problems in } \\
\text { personal life }\end{array}$ & 23.7 & 33.3 & 22.4 & 15.8 & 20.3 \\
\hline $\begin{array}{l}\text { Successful } \\
\text { marriage }\end{array}$ & 9.8 & 11.1 & 10.2 & 5.3 & 10.8 \\
\hline Nothing to do & 6.3 & 1.6 & 2.0 & 13.2 & 9.5 \\
\hline
\end{tabular}

to women). $47.0 \%$ of respondents believe that the reason for weight loss was health problems, $38.0 \%$ - low self-esteem, $29.0 \%$ - the influence of the media and society and $24.0 \%$ - problems referring to their personal live. The least popular answer is underlined by the fact that those who are losing weight have nothing to do (6\%).

The study has shown that the majority of respondents (72.0\%) do not consider model parameters of the figure to be the standard. However, girls still relate to such ideals somewhat more favourably than boys. Perhaps this is due to the greater exposure of girls to the influence of the media, public opinion and advertising. The dependence of the attempt and desire to lose weight on the adoption of model parameters for the standard was not found.

A typological analysis has revealed three main types of students (Table2): losing weight a certain amount of time and wanting to achieve a specific result ("I need to lose $5 \mathrm{~kg}$ in two weeks"), losing weight without a time limit, but wanting to achieve a result ("I'll lose weight, until I lose weight by $5 \mathrm{~kg}$ "), losing weight without a time limit and without a specific goal ("I will lose weight"). The basis for our typology is availability of time frames and students' goals. Most often, students before losing weight nevertheless clearly present the purpose of their weight loss. Weight loss succeeds in almost $90 \%$ of cases of having a time frame and goal or lack of both. Weight loss with a time frame and lack of a goal and weight loss with a lack of a time frame and setting a goal are slightly 
less successful, but still effective. Most often, losing weight is not tied to any event (45\%), and such weight loss is the least successful - only $59 \%$ of students manage to lose weight. Often students lose weight by the beach season (18\%) or the beginning of a new phase in life (14\%) to create a beautiful body.

TABLE 2: Dependence of the time frame and goals of losing weight on gender (percentage of the number of questioned respondents)

Time frame and
purpose
Both the time frame
and the goal are set
Lack of time frame,
the goal is set
Neither the time
frame nor the goal is
se
The time frame is set,
the goal is not set
Amount:
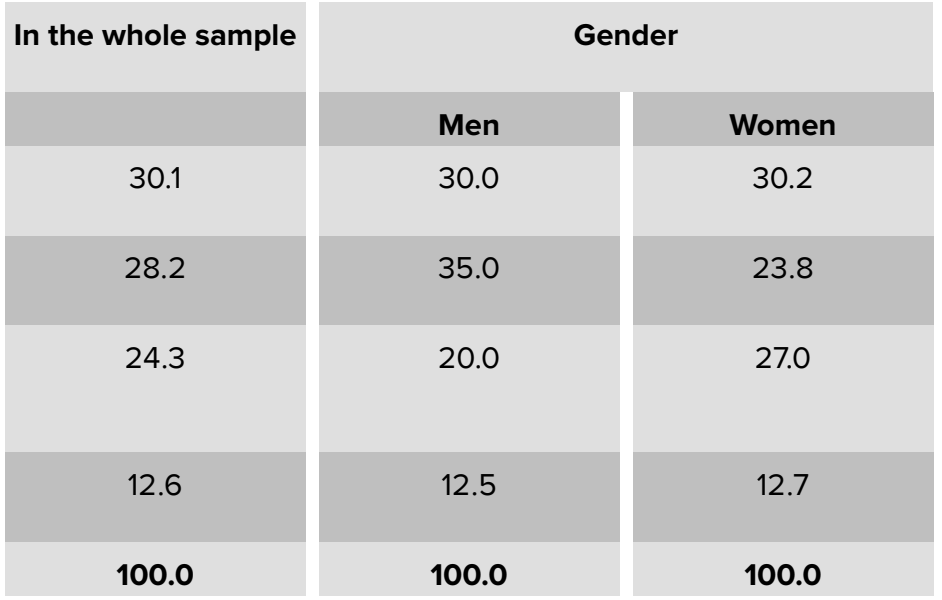

The study has fixed that students' satisfaction is not always achieved after weight loss. It turned out that after a noticeable weight loss, every fifth girls and every tenth young men considers himself / herself stout. Every third girl and every third young man seems that she / he would like to lose some more weight and only every third student feels comfortable. That is, every third student achieves a sense of comfort and satisfaction with his / her physicality, but for the rest respondents it seems that they need to continue to change their physicality. However, respondents are not ready for more radical measures (plastic surgery, etc.).

\section{Conclusions}

The survey has fixed different gender stereotypes of the demanded male and female body, in principle, those that modern mass media broadcast.

For the majority of students, the sociocultural practice of weight loss is a means of constructing their physicality. However, for only one third of the respondents it is effective.

The study has shown that the main students' reason for weight loss is their desire to have an ideal and a demanded body in their community. The typological analysis has determined three types of students. The basis for our typology is availability of time frames and students' goals to lose weight. 
The study has elucidated the fact that students are not ready to use more radical sociocultural practices to change their physicality such as plastic surgery, etc.

Based on these findings and current results, future researches may study the sociocultural practices of weight loss as a means of shaping the demanded body in various socio-demographic groups of Russians.

Our conclusions referring yo the sociocultural practice of weight loss as a means of shaping a demanded body in the student's community are important for fitness trainers, nutritionists, beauty salons, etc., dealing with health, beauty, body design, etc.

\section{Acknowledgments}

The study was supported by the South Ural State University (National Research University).

\section{References}

[1] Azarenko, S. A. (2006). Body Community. Moscow: Academ. Proect, p. 243.

[2] Aalten, A. (1997). Performing the Body, Creating Culture. European Journal of Women's Studies, vol. 4, issue 2, pp. 38-47.

[3] Berger, P. and Luckman, T. (1979). The Social Construction of Reality:A Treatise in the Sociology of Knowledge. Harmondsworth: Penguin.

[4] Bolton, M. A., et al. (2003). Measuring Outcomes in Plastic Surgery: Body Image and Quality of Life in Abdominoplasty Patients. Plast Reconstr Surg, vol. 112, pp. 619-25.

[5] Bourdieu, P. (1980). Le Sens pratique. Paris: Minuit, La France, p. 475.

[6] Bourdieu, P. (1994). Beginning. Moscow: Nauka. p. 432.

[7] Crerand, C. E., Menard, W. and Phillips, K. A. (2010). Surgical and Minimally Invasive Cosmetic Procedures among Persons with Body Dysmorphic Disorder. Ann Plast Surg, vol. 65, pp. 11-16.

[8] Crossley, N. (2006). In the Gym: Motives, Meanings and Moral Careers. Body and Society, vol. 12, issue 3, pp. 23-50, doi.org/10.1177/1357034X06067154.

[9] Foucault, M. (1968). The History of Sexuality, the Care of the Self. New York: Pantheon books.

[10] Gambles, R., Lewis, S. and Rapoport, R. (2006). The Myth of Work - Life Balance: The Challenge of Our Time for.4Men, Women and Societies. Chichester: John Wiley \& Sons. 
[11] Golman, E. A. (2014). Development of Ideas about Bodily Practices in Social Science. Sociological studies, vol. 10, pp. 127-136.

[12] Garfinkel, H. (1986). Ethnomethodological Studies of Work. London: Routledge \& Kegan Paul, p. 523.

[13] Giddens, E. (2005). Organization of Society: Essay on the Theory of Structure. Moscow: Academic Project, p. 582.

[14] Kurakin, D. (2011). Models of the Body in the Modern Popular and Expert Discourse: Towards the Cultural-Sociological Perspective of Analysis. Sociological Review, vol. 10 , issue $1-2$, pp. 56-74.

[15] Krueger, J. I., et al. (2003). Perceptions of Trait Typicality in Gender Stereotypes: Examining the Role of Attribution and Categorization Processes. Personality \& Social Psychology Bulletin, vol. 29, issue 1, pp. 108-116.

[16] Litvinova, T. A. (2012). Body and Physicality: The Content of Concepts and the Main Approaches to Study. Bulletin of Tver State University. Series: Philosophy, vol. 4, pp. 204-213.

[17] Merenkov, A. V. (2019). The Demanded Body in the Representations of School Students. Logos et Praxis, vol. 18, issue 3, pp. 78-87.

[18] Peat, C. M., Peyerl, N. L. and Muehlenkamp, J. J. (2008). Body Image and Eating Disorders in Older Adults: A Review. Journal of General Psychology, vol. 135, pp. 343-358.

[19] Romanovsky, N. V. (2006). The Human Body - New Horizons of Social Cognition. Sociological research, vol. 4, pp. 16-25.

[20] Siep, L. (2003). Normative Aspects of the Human Body. Journal of Medicine and Philosophy, vol. 28, issue 2, pp. 171-185.

[21] Turner, B. S. (2008). The Body and Society: Explorations in Social Theory ( $3^{\text {rd }}$ ed.). London: SAGE Publications, p. 345.

[22] Schutz, A. (2003). The Semantic Structure of the Everyday World: Essays on Phenomenological Sociology. Moscow: Institute of the Public Opinion Foundation, p. 336. 